\title{
The Predictive Value of C-Reactive Protein in End-Stage Renal Disease: Is It Clinically Significant?
}

\author{
Frank M. van der Sande Jeroen P. Kooman Karel M.L. Leunissen \\ Division of Internal Medicine and Nephrology, University Hospital Maastricht, Maastricht, The Netherlands
}

\section{Key Words}

C-reactive protein $\cdot$ End-stage renal disease $\cdot$ Predictive value, $\mathrm{C}$-reactive protein

\begin{abstract}
Cardiovascular disease is the leading cause of death in patients with end-stage renal disease. Besides traditional risk factors, disturbances in mineral and bone metabolism and inflammation are thought to be responsible for the increased risk of death. In the last years C-reactive protein (CRP) has gained a lot of attention in the general population, especially with regard to its link with atherosclerosis. Although several studies suggest that CRP may be useful as a parameter in predicting future cardiovascular events in both the general population and in patients with end-stage renal disease, there is doubt about the clinical evidence of this assumption. A statistical association between CRP and cardiovascular disease was observed in various studies, but the predictive power of this association is markedly diminished when adjusted for other risk factors. The relative contributions of CRP as a marker, as a causative agent, or as a consequence of atherosclerotic vascular disease are unclear, both in the general population and in the dialysis population. The CRP levels are highly variable and influenced
\end{abstract}

Presented at the International Conference on Dialysis VII, New Orleans, La., January 2005.
(C) 2006 S. Karger AG, Basel 0253-5068/06/0244-0335\$23.50/0

Fax +4161306 1234 E-Mail karger@karger.ch www.karger.com www.karger.com/bpu by intercurrent events in dialysis patients. In dialysis patients, it is possible to reduce the CRP levels by statins, although these agents do not reduce the cardiovascular mortality in diabetic dialysis patients.

Copyright () 2006 S. Karger AG, Basel

\section{Introduction}

One of the most important advances in medicine was the identification of the major risk factors for atherosclerotic vascular disease, arising from large prospective studies, such as the Framingham Heart Study [1] and the Seven Countries Study [2]. The major modifiable risk factors in an apparently 'healthy' population include elevated blood pressure, dyslipidemia, smoking, and diabetes mellitus. In recent years, a number of new candidate risk factors or markers have been proposed as significant predictors of atherosclerosis and its complications [3]. Especially $\mathrm{C}$-reactive protein (CRP) as a nontraditional risk factor has gained a lot of attention in the relation between inflammation and atherosclerosis.

Cardiovascular disease is the major cause of morbidity and mortality in patients with end-stage renal disease, leading to death rates of about $50 \%$ in dialysis patients [4]. Whereas the relation between traditional risk factors, such as hypertension and dyslipidemia, and cardiovascular mortality is not straightforward, inflammation as characterized by an increased CRP level is clearly associated with an increased mortality in this population [5].

Frank M. van der Sande, MD, $\mathrm{PhD}$

Department of Internal Medicine and Nephrology

University Hospital Maastricht, P. Debyelaan 25, PO Box 5800

6202 AZ Maastricht (The Netherlands)

Tel. +31 43387 5007, Fax +31 43387 5006, E-Mail fvs@groupwise.azm.nl 
Thus, it would appear rational to use the CRP level as a predictor for cardiovascular disease and a target for therapy, not only in the 'healthy' general population, but especially in dialysis patients.

There is ample evidence that inflammation is an integral part of the process of atherosclerosis [6]. A series of studies performed in the general population found a significant positive relationship between CRP concentration and coronary artery disease [7-9]. Moreover, several prospective epidemiological studies performed in the United States and in Europe have demonstrated that CRP is a predictor of future coronary events among apparently healthy men and women [10]. Hence, a 70-yearold test used to detect acute inflammation has become a potentially important marker for cardiovascular disease. The question that should be answered is: does CRP improve the prediction of atherosclerotic disease above that of traditional risk factors?

However, before introducing a new risk factor, one has to consider whether the new risk factor provides a clinically significant prognostic value above and beyond that provided by traditional risk factors. In addition, the risk factor should be sensitive and specific for the disease. Moreover, reduction in the level of the risk factor should lead to clinical benefit. Based on these premises, the potential benefits and drawbacks of CRP as a potential risk factor predictor for cardiovascular disease, with special attention to patients with end-stage renal disease, will be discussed.

\section{C-Reactive Protein}

CRP is a nonglycosylated protein produced by human hepatocytes in response to infection, inflammation, or tissue damage. It is composed of five identical noncovalently linked subunits that form a symmetrical pentagonal structure with a molecular weight of 105,000 Da. CRP was originally named for its ability to precipitate somatic C-polysaccharide of pneumococci; however, other methods are now used to detect it. CRP is present at very low levels in the normal population. Levels $<1 \mathrm{mg} / \mathrm{dl}$ are considered insignificant, levels from 1 to $10 \mathrm{mg} / \mathrm{dl}$ are considered moderately elevated, and levels $>10 \mathrm{mg} / \mathrm{dl}$ are markedly elevated. Before quantitative methods for CRP were developed, CRP was reported as 'present' or 'absent'. Nowadays, several methods are commercially available in clinical laboratories for measurement of CRP: the most commonly used are either immunonephelometric or immunoturbidimetric assays. These methods are gen- erally reproducible, fully automated, and capable of measuring CRP with a detection limit of 3-5 mg/l. Although this detection limit is adequate for the traditional clinical utility of CRP in monitoring infections, it renders most of the current assays useless in assessing and predicting the risk of coronary and cerebrovascular diseases in apparently healthy populations.

In contrast, most of the original studies mentioned in this article that examined the clinical utility of CRP in predicting future myocardial infarction and stroke have used newly developed high-sensitivity tests for CRP [11]. These ultrasensitive enzyme-linked immunosorbent assays are capable of measuring CRP at a concentration of $0.007 \mathrm{mg} / \mathrm{l}$. However, this methodology is primarily for research and is not ideal for routine use in highly automated clinical laboratories. Recently, an ultrasensitive latex-enhanced immunoassay for CRP measurement on the BN II nephelometer (Dade Behring, Newark, Del., USA) has been evaluated and validated clinically [11]. This assay uses monoclonal anti-CRP antibodies, by which the specific antibodies coat to polystyrene particles to form a complex with the CRP present in the study sample. Based on these data it seems to be preferable to use high-sensitivity CRP measurements, since with this method inflammation at a low level of CRP can be detected.

Although high-sensitivity CRP measurements may enhance our prognostic and therapeutic capabilities, their value has not been fully established.

\section{Other Markers of Inflammation}

In the general population, IL-6 has been shown to be superior to CRP in predicting outcome [12, 13]. Recently, it has also been suggested that markers of inflammation such as IL-6 and fetuin-A might be of more importance than CRP in predicting the outcome in renal patients [1417]. What the beneficial effects in terms of prediction of outcome of IL-6 and other markers of inflammation are has to be determined in further studies, especially since the risk ratio of IL-6 is close to that of CRP.

\section{Role of CRP in the Pathogenesis of Cardiovascular Disease}

Numerous studies have shown that CRP is of importance in the pathogenesis of vascular disease. CRP elicits a multitude of effects on endothelial biology, favoring a 
proinflammatory and proatherosclerotic phenotype. In vitro experiments revealed that CRP potently downregulates endothelial nitric oxide synthase transcription and destabilizes endothelial nitric oxide synthase mRNA, resulting in a decreased release of basal and stimulated nitric oxide, known to be an endothelium-derived relaxing factor [18]. Furthermore, CRP has been shown to stimulate endothelin-1 and IL-6 release from endothelial cells, to upregulate adhesion molecules such as intercellular adhesion molecule-1, vascular cell adhesion molecule-1, and E-selectin, and to stimulate the release of monocyte chemotactic protein-1, a chemokine that facilitates leukocyte transmigration [19-21]. By inhibiting the nitric oxide production, CRP facilitates endothelial cell apoptosis and blocks angiogenesis. Furthermore, CRP potently upregulates nuclear factor- $\mathrm{B}$, directly upregulates angiotensin type 1 receptor in vascular smooth muscle cells in vitro and in vivo, and stimulates vascular smooth muscle migration and proliferation, neointimal formation, and reactive oxygen species production [22, 23]. Finally, it has been suggested that CRP upregulates complement-inhibitory proteins and protects endothelial cells from complement-mediated cell injury on the one hand, whereas on the other hand it may activate the complement system and is involved in foam cell formation, thereby promoting atherosclerotic lesions [24-26]. This suggests that a balance of proatherogenic and antiatherogenic effects of CRP on the vessel wall may be important in the development of atherosclerosis. However, also the presence of atherosclerosis itself may induce an inflammatory process, suggesting that CRP might be a epiphenomenon of disease.

\section{CRP and Cardiovascular Disease in the General Population}

Data from the Framingham risk study showed that the relative risks of future vascular disease are related to CRP values, with the highest risk in the highest quintile [27]. In another study, Ridker et al. [28] evaluated the relationships between CRP, metabolic syndrome, and incident cardiovascular events among more than 14,000 apparently healthy women who were followed up for an 8-year period for myocardial infarction, stroke, coronary revascularization, or cardiovascular death. Of the cohort, 24\% had the metabolic syndrome (defined as upper-body obesity, hypertriglyceridemia, low high-density lipoprotein cholesterol levels, hypertension, and abnormal glucose concentrations) at study entry. The patients were stratified into three groups, having CRP levels $<1$, between 1 and 3 , and $>3 \mathrm{mg} / \mathrm{l}$. Patients in the highest tertile, i.e., a CRP level $>3 \mathrm{mg} / \mathrm{l}$, had a relative risk of 2.1 times that of those with metabolic syndrome who had the lowest CRP levels, i.e., $<1 \mathrm{mg} / \mathrm{l}$. So, CRP seems to be of statistical value in predicting atherosclerotic vascular disease among individuals already defined as having the metabolic syndrome. However, is it possible, based on CRP, to discriminate clinically between those with and those without disease, but what are the optimal reference intervals to discriminate between disease and no disease?

Harris et al. [29] could demonstrate in a prospective study of almost 1,300 healthy nondisabled participants that higher circulating levels of IL-6 and CRP were associated with mortality in this population-based sample of healthy older persons. However, also a wide overlap of the confidence interval in the different quartiles of CRP in patients with and without any cardiovascular disease was observed, suggesting that CRP does not discriminate clinically between patients with and without disease. Moreover, participants with high IL-6 levels in the absence of high CRP levels also had an increased risk of death, whereas high CRP levels in the absence of high IL-6 levels were not associated with mortality [29]. The limitation of this study is that there was no objective evaluation of the presence or not of cardiovascular disease, but of possible severe disease versus unknown. Out of more than 20,000 US males, aged between 40 and 84 years, participating in the Physicians' Health Study, Ridker et al. [30] prospectively studied 543 patients and 543 controls [30]. The baseline CRP levels were higher in men who experienced myocardial infarction or ischemic stroke at a later stage as compared with men without vascular events. The data of the study showed that the median CRP concentration of men who did not develop cardiac disease was $1.13 \mathrm{mg} / \mathrm{l}$, while the median value for persons who developed myocardial infarction was $1.51 \mathrm{mg} / \mathrm{l}$, with a range from 0.55 to $2.11 \mathrm{mg} / \mathrm{l}$. Thirty percent the of men who did not develop cardiovascular events at a later stage were in the highest two quartiles, suggesting a high overlap in those developing myocardial infarction with those who did not. Data from the National Health and Nutrition Examination Survey [31] showed that $40 \%$ of the women aging between 30 and 39 years had high-sensitivity CRP results $>3.5 \mathrm{mg} / 1$ and that this high proportion was similar in healthy women and in those on hormone replacement therapy. However, the risk of coronary events in these women was very low [31]. Finally, the recent study performed by Danesh et al. [32] compared 2,459 patients who had a nonfatal myocardial infarction or died of coronary disease during a 12-year study period with 3,969 controls. The calculated 
areas under the receiver operating characteristic curves indicated that information on CRP provided little additional predictive value as compared with that provided by major established risk factors such as hypertension, cholesterol level, and current cigarette smoking. Although the authors used a high-sensitivity CRP measurement cutoff value of of $2 \mathrm{mg} / \mathrm{l}$, in contrast to the $3 \mathrm{mg} / \mathrm{l}$ used in many other studies, they reported that based on their results and an updated meta-analysis of more than 4,000 patients the value of CRP measurements in the prediction of the risk of coronary disease was overestimated and that established coronary disease risk factors are generally stronger predictors than are CRP values.

The CDC/AHA Workshop on Markers of Inflammation and Cardiovascular Disease [33] examined selection and use of inflammatory markers to predict cardiovascular disease based on the evidence reported in the literature. It was concluded that there was insufficient evidence to support the use of CRP as a clinical tool to predict future cardiovascular events.

To summarize, although related to cardiovascular events, there is a wide overlap of CRP in patients with and without any cardiovascular disease. Moreover, it is not yet fully clear whether CRP has a causal effect or is an epiphenomenon of disease.

\section{CRP in Patients with End-Stage Renal Disease}

The causes of chronic and low-grade inflammation in end-stage renal disease patients have been extensively discussed in the literature [34]. The processes, in brief, are promoted by several factors which may be related or not to dialysis. In dialysis patients, there is a combination of an impaired immune response related to the uremic state and persistent immune/inflammatory responses (blood-membrane contact, water quality, bioincompatible membranes, vascular access, etc.), resulting in persistent immune system stimulation, low-grade systemic inflammation, and altered cytokine balance. This may characterize the uremic state which may translate into an increased risk of developing vascular disease.

The problem with CRP is that it is a relatively nonspecific acute-phase reactant. Especially in dialysis patients, who are exposed to various factors such as bioincompatible membranes and nonsterile dialysate and often suffer from significant comorbidity that may lead to a state of chronic inflammation, CRP levels may vary widely, both intra- and interindividually. One needs detailed clinical information to put the diagnostic value of CRP in perspec- tive. To describe CRP as a general marker of cardiovascular disease might, therefore, be too simplistic. The prevalence of silent infections is high in dialysis patients. It was shown by Kaysen et al. [35] that the CRP level was significantly higher in dialysis patients with a low as compared with those having a normal albumin concentration. Van Tellingen et al. [36] studied prospectively the effect of acute-phase responses on the chronic inflammatory state in hemodialysis patients. CRP was measured at the start of the study and after 12 weeks. In addition to the microbiological quality of the dialysate, the occurrence of clinical events was assessed. There were several clinical events such as infections, shunt complications, diabetic ulcer, heart failure, total hip replacement, or subdural hematoma. Twenty-three percent of the patients had an increase in CRP levels $>8 \mathrm{mg} / \mathrm{l}$ during the follow-up period. The appearance of a clinical event during follow-up remained the only significant predictor of CRP accounting for $22.1 \%$ of its variance. In another study [37], a large variability in CRP levels was noted, and, furthermore, changes in CRP levels were related to intermittent or chronic (co)morbidity. The CRP levels were assessed at monthly intervals in 60 dialysis patients over a 3-month period. Moreover, all patients were seen weekly in groups, and special emphasis was placed on intermittent clinical events. The study showed that in $92 \%$ of the patients the CRP level was $>2 \mathrm{mg} / \mathrm{l}$ on at least one occasion. In $68 \%$ of the patients, the CRP concentration was $>10 \mathrm{mg} / \mathrm{l}$ on at least one measurement, and in $96 \%$ of these patients a significant clinical event and/or chronic comorbidity was observed.

Studies on the significance of higher levels of CRP in end-stage renal disease patients as compared with higher levels of CRP in high-risk groups are lacking. The above data suggest that when there is an elevated CRP level in end-stage renal disease patients, there might be evidence of an intercurrent clinical event. Moreover, comparing higher levels of CRP in patients with chronic kidney disease with those of other nonrenal groups is even more difficult, since several studies [38, 39] have shown that a decline in renal function leads to an accumulation of cytokines, such as IL-6, which may be partly responsible for the increased level of CRP in chronic kidney disease.

\section{Treatment of Increased CRP Levels in the General Population}

Testing of CRP may provide some prognostic information; however, it is not known whether CRP levels provide a target for treatment to enhance survival, like lowering of 
low-density lipoprotein cholesterol. Lifestyle modification provides the first opportunity to modify the CRP levels, because obesity, smoking, diabetes, and other factors are associated with elevated CRP concentrations. There is strong evidence that the benefits of risk reduction strategies, including aspirin and statins, are markedly enhanced in patients with elevated CRP levels [40-42]. However, whether lowering of the CRP concentration reduces the cardiac risk is not known until now. Furthermore, to know whether pharmacological treatment of patients with only an elevated level of CRP is warranted will require further trials. Several therapeutic interventions, which are known to reduce cardiovascular mortality, are also able to reduce the CRP levels. It has been suggested that part of the therapeutic power of statins and aspirin results from their antiinflammatory effects. Statins appear to reduce the cardiovascular risk irrespective of the lipid-lowering effect [40, 41]. Moreover, statins reduce the CRP concentration in patients without overt hyperlipidemia [42].

However, at present it is not known whether the decline in CRP levels represents an epiphenomenon, showing a reduced inflammatory status due to reversal of atherosclerosis, or whether a reduction in CRP concentrations per se has an independent therapeutic effect. In an interesting study published in 2003 [43], it was shown that statins reduce the CRP levels but not the concentrations of IL-6 which is the main stimulus for CRP.

Bhatt and Topol [44] proposed an algorithm for utilization of CRP to allocate medical therapy. In patients who have had a cardiovascular event (secondary prevention) and who were already on basic therapy that included statin and aspirin every 2 weeks, the CRP concentration was determined. If the CRP levels remained elevated $>1.5 \mathrm{mg} / \mathrm{l}$, the next medication in the algorithm, such as an angiotensin-converting enzyme inhibitor or clopidrogel or a fibrate or thiazolidinedione, would be prescribed. If an added agent had no effect on the CRP level, then it would be discontinued. The results of such an algorithm would validate whether an anti-inflammatory strategy or tailored medical therapy can reduce the incidence of death, myocardial infarction, and stroke. However, clinical data on the effectiveness of such an algorithm are not yet available.

\section{Treatment of Increased CRP Levels in Patients with End-Stage Renal Disease}

It was shown by several authors $[45,46]$ that the CRP concentration was significantly reduced in patients with end-stage renal disease using statins as compared with placebo $[45,46]$. However, until recently, results of randomized controlled trials toward the effect of statins on mortality in dialysis patients were lacking. The study performed by the German Diabetes and Dialysis Study Investigators [47] was the first to examine the use of statins in type 2 diabetics with kidney failure or end-stage renal failure as well as to study the cardiovascular outcomes in dialysis patients overall. The study included 1,255 diabetics at 178 dialysis centers throughout Germany. A large proportion of the patients suffered from hypertension, congestive heart failure, and peripheral arterial and cardiac diseases. Twenty to thirty percent of the patients had suffered a prior heart attack or had undergone revascularization and heart surgery. The patients were randomized to atorvastatin $20 \mathrm{mg}$ or placebo. The composite end points were cardiovascular death, nonfatal myocardial infarction, or stroke. The mean low-density lipoprotein cholesterol level was $126 \mathrm{mg} / \mathrm{dl}$ in the study population.

In the atorvastatin-treated patients, the low-density lipoprotein cholesterol concentration was reduced by $41 \%$. Overall, there were no significant differences in outcomes between placebo- and atorvastatin-treated patients. However, the relative risk of fatal stroke among those receiving atorvastatin was significantly higher as compared with the placebo group. So, statins seem to reduce the CRP levels in dialysis patients, but they do not reduce the cardiovascular mortality.

\section{Conclusions}

Evidence supports a statistical association between CRP levels and cardiovascular disease, but the predictive power of this association is markedly diminished when adjusted for other risk factors. The relative contributions of CRP as a marker, a causative agent, or a consequence of atherosclerotic vascular disease are unclear, both in the general 'healthy' population and in the dialysis population. The CRP levels are highly variable and influenced by intercurrent events in dialysis patients. In dialysis patients, it is possible to reduce the CRP levels by statins without an apparent reduction in cardiovascular mortality. In conclusion, more studies are necessary to prove the concept of the clinical utility of CRP as a risk factor predictor and target for therapeutic interventions in dialysis patients.

Blood Purif 2006;24:335-341

Predictive Value of C-Reactive Protein in 


\section{References}

11 Wilson PW, D'Agostino RB, Levy D, Belanger AM, Silbershatz H, Kannel WB: Prediction of coronary heart disease using risk factor categories. Circulation 1998;97:1837-1847.

2 Keys A: Seven Countries: A Multivariate Analysis of Death and Coronary Heart Disease. Cambridge, Harvard University Press, 1980.

-3 Hackam DG, Anand SS: Emerging risk factors for atherosclerotic vascular disease: a critical review of the evidence. JAMA 2003;290:932940.

4 Foley RN, Parfrey PS, Sarnak MJ: Clinical epidemiology of cardiovascular disease in chronic renal disease Am J Kidney Dis 1998;32(suppl 3):S112-S119.

5 Collins AJ, Shuling L, Ma JZ, Herzog C: Cardiovascular disease in end-stage renal disease patients. Am J Kidney Dis 2001;38(suppl 1): S26-S29.

-6 Ross R: Atherosclerosis - an inflammatory disease. N Engl J Med 1999;340:115-126.

7 Haverkate F, Thompson SG, Pyke SD, Gallimore JR, Pepys MB: Production of C-reactive protein and risk of coronary events in stable and unstable angina. Lancet 1997;349:462466.

8 Libby P, Ridker PM: Novel inflammatory markers of coronary risk: theory versus practice. Circulation 1999;100:1148-1150.

-9 Tracy RP: Inflammation in cardiovascular disease: cart, horse, or both. Circulation 1998;97: 2000-2002.

10 Ridker PM, Cushman M, Stampfer MJ, Tracy $\mathrm{RP}$, Hennekens $\mathrm{CH}$ : Inflammation, aspirin, and the risk of cardiovascular disease in apparently healthy men. N Engl J Med 1997;336: 973-979.

11 Rifai N, Tracy RP, Ridker PM: Clinical efficacy of an automated high-sensitivity C-reactive protein assay. Clin Chem 1999;45:21362141

12 Vasan RS, Sullivan LM, Roubenoff R, Dinarello CA, Harris T, Benjamin EJ, Sawyer DB, Levy D, Wilson PW, D'Agostino RB: Inflammatory markers and risk of heart failure in elderly subjects without prior myocardial infarction: the Framingham Heart Study. Circulation 2003;107:1486-1491.

$\checkmark 13$ Cesari M, Penninx BW, Newman AB Kritchevsky SB, Nicklas BJ, Sutton-Tyrrel K, Tracy RP, Rubin SM, Harris TB, Pahor M: Inflammatory markers and cardiovascular disease: the Health, Aging and Body Composition (Health ABC) Study. Am J Cardiol 2003;92: 522-528.

14 Pecoits-Filho R, Barany P, Lindholm B, Heimburger O, Stenvinkel P: Interleukin-6 is an independent predictor of mortality in patients starting dialysis treatment. Nephrol Dial Transplant 2002;17:1684-1688.
15 Panichi V, Maggiore U, Taccola D, Migliori M, Rizza GM, Consani C, Bertini A, Sposini S, Perez-Garcia R, Rindi P, Palla R, Tetta C: Interleukin-6 is a stronger predictor of total and cardiovascular mortality than C-reactive protein in haemodialysis patients. Nephrol Dial Transplant 2004;19:1154-1160.

16 Stenvinkel P, Wang K, Qureshi AR, Axelsson J, Pecoits-Filho R, Gao P, Barany P, Lindholm B, Jogestrand T, Heimburger O, Holmes C, Schalling M, Nordfors L: Low fetuin-A levels are associated with cardiovascular death: impact of variations in the gene encoding fetuin. Kidney Int 2005;67:2383-2392.

17 Tripepo G, Mallamaci F, Zoccali C: Inflammation markers, adhesion molecules, and allcause and cardiovascular mortality in patients with ESRD: searching for the best risk marker by multivariate modeling. J Am Soc Nephrol 2005;16(suppl 1):S83-S88.

18 Verma S, Wang CH, Li SH, Dumont AS, Fedak PW, Badiwala MV, Dhillon B, Weisel RD, Li RK, Mickle DA, Stewart DJ: A self-fulfilling prophecy: $\mathrm{C}$-reactive protein attenuates nitric oxide production and inhibits angiogenesis. Circulation 2002;106:913-919

19 Verma S, Li SH, Badiwala MV, Weisel RD, Fedak PW, Li RK, Dhillon B, Mickle DA: Endothelin antagonism and interleukin-6 inhibition attenuate the proatherogenic effects of C-reactive protein. Circulation 2002; 105: 1890-1896.

20 Pasceri V, Willerson JT, Yeh ET: Direct proinflammatory effect of C-reactive protein on human endothelial cells. Circulation 2000; 102:2165-2168.

21 Pasceri V, Chang JS, Willerson JT, Yeh ET: Modulation of C-reactive protein-mediated monocyte chemoattractant protein-1 induction in human endothelial cells by anti-atherosclerosis drugs. Circulation 2001;103:2531-2534.

22 Verma S, Badiwala MV, Weisel RD, Li SH, Wang CH, Fedak PW, Li RK, MIckle DA: Creactive protein activates the $\mathrm{NF \kappa B}$ signalling pathway in saphenous vein endothelial cells: implications for atherosclerosis and restenosis. J Thorac Cardiovasc Surg 2003;126:18861891.

23 Wang CH, Li SH, Weisel RD, Fedak PW, Dumont AS, Szmitko PE, Li RK, Mickle DA, Verma S: C-reactive protein upregulates angiotensin type 1 receptors in vascular smooth muscle. Circulation 2003;107:1783-1790.

24 Li SH, Szmitko PE, Weisel RD, Wang CH, Fedak PW, Li RK, Mickle DA, Verma S: C-reactive protein upregulates complement-inhibitory factors in endothelial cells. Circulation 2004; 109:833-836.

25 Torzewski J, Torzewski M, Bowyer DE, Fröhlich M, Koenig W, Waltenberger J, Fitzsimmons C, Hombach V: C-reactive protein frequently colocalizes with the terminal complement complex in the intima of early atherosclerotic lesions of human coronary arteries. Arterioscler Thromb Vasc Biol 1998; 18: 1386-1392.
26 Stenvinkel P, Lindholm B: C-reactive protein in end-stage renal disease: are there reasons to measure it? Blood Purif 2005;23:72-78.

27 Ridker PM, Rifai N, Rose L, Buring JE, Cook NR: Comparison of C-reactive protein and low-density lipoprotein cholesterol levels in the prediction of first cardiovascular events. $\mathrm{N}$ Engl J Med 2002;347:1557-1565.

28 Ridker PM, Buring JE, Cook NR, Rifai N: Creactive protein, the metabolic syndrome, and risk of incident cardiovascular events: an 8year follow-up of 14,719 initially healthy American women. Circulation 2003; 107:391397.

29 Harris TB, Ferrucci L, Tracy RP, Corti MC, Wacholder S, Ettinger WH Jr, Heimovitz H, Cohen HJ, Wallace R: Associations of elevated interleukin-6 and C-reactive protein levels with mortality in the elderly. Am J Med 1999; 106:506-512.

- 30 Ridker PM, Cushman M, Stampfer MJ, Tracy $\mathrm{RP}$, Hennekens $\mathrm{CH}$ : Inflammation, aspirin, and the risk of cardiovascular disease in apparently healthy men. N Engl J Med 1997;336: 973-979.

- 31 Ford ES, Giles WH, Mokdad AH, Myers GL: Distribution and correlates of C-reactive protein concentrations among adult US women. Clin Chem 2004:50:574-581.

32 Danesh J, Wheeler JG, Hirschfield GM, Eda S, Eiriksdottir G, Rumley A, Lowe GD, Pepys $\mathrm{MB}$, Gudnason V: C-reactive protein and other circulating markers of inflammation in the prediction of coronary heart disease. N Engl J Med 2004;350:1387-1397.

33 Smith SC Jr, Anderson JL, Cannon RO 3rd, Fadl YY, Koenig W, Libby P, Lipshultz SE, Mensah GA, Ridker PM, Rosenson R; CDC; AHA: CDC/AHA Workshop on Markers of Inflammation and Cardiovascular Disease: Application to Clinical and Public Health Practice: report from the clinical practice discussion group. Circulation 2004; 110:e550-e553.

34 Stenvinkel P, Ketteler M, Johnson RJ, Lindholm B, Pecoits-Filho R, Riella M, Heimburger O, Cederholm T, Girndt M: IL-10, IL-6, and TNF- $\alpha$ : central factors in the altered cytokine network of uremia - the good, the bad, and the ugly. Kidney Int 2005;67:1216-1233.

35 Kaysen GA, Stevenson FT, Depner TA: Determinants of albumin concentration in hemodialysis patients. Am J Kidney Dis 1997;29:658668.

36 van Tellingen A, Grooteman MP, Schoorl M, Bartels PC, Schoorl M, van der Ploeg T, ter Wee PM, Nube MJ: Intercurrent clinical events are predictive of plasma $\mathrm{C}$-reactive protein levels in hemodialysis patients. Kidney Int 2002;62:632-638 
-37 Beerenhout CH, Kooman JP, van der Sande FM, Hackeng C, Leunissen KM: C-reactive protein levels in dialysis patients are highly variable and strongly related to co-morbidity. Nephrol Dial Transplant 2003;18:221.

-38 Nakamura A, Suzuki T, Kohsaka T: Renal tubular function modulates urinary levels of interleukin-6. Nephron 1995; 70:416-420.

>39 Pecoits-Filho R, Heimburger O, Barany P, Suliman M, Fehrman-Ekholm I, Lindholm B, Stenvinkel P: Associations between circulating inflammatory markers and residual renal function in CRF patients. Am J Kidney Dis 2003; 41:1212-1218.

40 Ridker PM, Rifai N, Pfeffer MA, Sacks FM, Moye LA, Goldman S, Flaker GC, Braunwald E: Inflammation, pravastatin, and the risk of coronary events after myocardial infarction in patients with average cholesterol levels. Circulation 1998;98:839-844.
41 Ridker PM, Cannon CP, Morrow D, Rifai N, Rose LM, McCabe CH, Pfeffer MA, Braunwald E: C-reactive protein levels and outcomes after statin therapy. N Engl J Med 2005;352: 20-28.

42 Ridker PM, Rifai N, Clearfield M, Downs JR, Weis SE, Miles JS, Gotto AM Jr: Measurement of C-reactive protein for the targeting of statin therapy in the primary prevention of acute coronary events. N Engl J Med 2001;344:1959_ 1965.

43 März W, Winkler K, Nauck M, Böhm BO, Winkelmann BR: Effects of statins on C-reactive protein and interleukin-6: the Ludwigshafen Risk and Cardiovascular Health study. Am J Cardiol 2003;92:305-308.
44 Bhatt DL, Topol EJ: Need to test the arterial inflammation hypothesis. Circulation 2002; 106:136-140.

45 Ichihara A, Hayashi M, Ryuzaki M, Handa M, Furukawa T, Saruta T: Fluvastatin prevents development of arterial stiffness in haemodialysis patients with type 2 diabetes mellitus. Nephrol Dial Transplant 2002;17:15131517.

46 Chang JW, Yang WS, Min WK, Lee SK, Park JS, Kim SB: Effects of simvastatin on high-sensitivity C-reactive protein and serum albumin in hemodialysis patients. Am J Kidney Dis 2002;39:1213-1217.

47 Wanner C, Krane V, März W, Olschewski M, Mann JF, Ruf G, Ritz E; German Diabetes and Dialysis Study Investigators: Atorvastatin in patients with type 2 diabetes mellitus undergoing hemodialysis. N Engl J Med 2005;353: 238-248. 